\title{
Design of horizontal and vertical subsurface flow constructed wetlands treating industrial wastewater
}

\author{
J. Mena ${ }^{1}$, L. Rodriguez ${ }^{1}$, J. Nuñez ${ }^{1}$, F. J. Fernández ${ }^{2}$ \\ \& J. Villaseñor ${ }^{2}$ \\ ${ }^{1}$ Research and Development Centre for the Recuperation of the \\ Environment (CIDRA), Spain \\ ${ }^{2}$ Department of Chemical Engineering, \\ University of Castilla-La Mancha, Spain
}

\begin{abstract}
Constructed wetlands have become a good alternative to urban and industrial wastewater treatments. Because of the many interactions between the different parts that form the wetland, the design of these systems used to be very complex so a good design tool is required. Hybrid constructed wetlands mix the aerobic and anaerobic properties of vertical and horizontal subsurface flow constructed wetlands to improve COD, phosphorous and, especially nitrogen removal. A simulation of the concentration profiles of these compounds into a hybrid system constituted by four vertical flow constructed wetlands and a horizontal flow one with the $\mathrm{K}-\mathrm{C}^{*}$ model was achieved when the system treated an urban and a winery wastewater, respectively. Maximum limits of the flow rate to achieve the legislation limits of the different pollutants were calculated. Winery wastewater treatment required lower flow rates because of its higher organic loading. Because constructed wetlands had limited capacity to remove phosphorous, it was the most restrictive pollutant, requiring a lower flow rate.
\end{abstract}

Keywords: constructed wetland, hybrid system, $K-C^{*}$ model, simulation.

\section{Introduction}

In the last few years, inside natural systems of wastewater treatment constructed wetland $(\mathrm{CW})$ has become an important alternative of treatment because it 
combines relatively high performances of pollutant removal with low maintenance and simple operation.

According to the type of flow, CWs can be differentiated in CWs with surface flow (SF) and with subsurface flow (SSF). Among the last type, we can discern between horizontal subsurface (HSSF) and vertical subsurface (VSSF) flow. Both of the SSF CWs can be used as a secondary treatment of wastewater in certain cases whereas SF CWs only should be used on tertiary treatments because that of the high loaded wastewaters using SF CWs can generate bad odours and mosquito proliferation [1].

HSSF CW is continuously fed from a side of the wetland. The depurated wastewater is collected in the opposite side, keeping all the soil saturated of water. Because of this fact, the opportunities of contact between air and water are limited and, in turn, the oxygen transference [1]. Although plants transport some oxygen from the atmosphere to the roots through the plant stems [2, 3], creating some aerobic zones, the main part of the soil is anaerobic [4] because of this limited contact. HSSF CW obtains good COD removal performance. With respect to the nitrogen, the limited oxygen availability decreases the nitrification and, in turn, the nitrogen removal performance despite the denitrification is very fast [5]. With respect to the phosphorous, its removal mechanisms are mainly physical (e.g. precipitation with $\mathrm{Ca}^{2+}, \mathrm{Al}^{3+}$ or $\mathrm{Fe}^{3+}$ that can be present in the soil material) [6-8], so they aren't influenced by oxygen concentration.

On the other hand, VSSF CW is sequentially fed throughout the entire surface of the wetland, collecting the depurated wastewater in the bottom of it. In this case, there are parts of the soil saturated and unsaturated of water. Hence, the contact between water and air is favoured and, in turn, the oxygen transference, increasing the aerobic zones in the soil [9]. VSSF CW obtains good COD removal performances too, but, with respect to the nitrogen, the higher availability of oxygen increases nitrification eliminating more nitrogen or, at least, converting the main part in ammoniacal nitrogen. With respect to the phosphorous, it is very similar to the HSSF CW.

Taking advantage of the characteristics of each SSF CW, there are some systems of wastewater treatment, named hybrid CW [9], that combine both types of SSF CW. First, wastewater is treated in a VSSF CW, where a great part of $\mathrm{COD}$ is removed and aerobic environment makes nitrification take place, converting the main part of nitrogen in nitrate. Finally, the effluent is treated in a HSSF CW, where the remaining COD is removed and anoxic environment makes denitrification take place, converting nitrate in nitrogen gas. Another scheme of hybrid CW is the treatment with the HSSF CW followed by the VSSF $\mathrm{CW}$ and a recirculation of part of the effluent of the VSSF one to the HSSF one. With this system, clogging, as HSSF support better high solids concentrations, is minimized. Moreover, the problem of COD lack in the denitrification mechanisms of the HSSF CW is avoided.

The aim of this work was to study of the design and construction of a system based on four VSSF CWs followed by one HSSF CW. Likewise, the capacity of treatment of two wastewaters (winery and urban) with CWs was established and predicted by using kinetic models. 


\section{Constructed wetland design}

CW consists of soil, water, plants and micro organisms and there are many interactions between them making the $\mathrm{CW}$ design to be very complex. So, an optimum design is critical to obtain good removal performances and to avoid operative problems.

There are different tools to $\mathrm{CW}$ design. They can be divided between mechanistic and non mechanistic models [10]. The mechanistic ones model mathematically all the main processes that are taking place in $\mathrm{CW}$. Langergraber [11] proposed a kinetic model (CW2D) implemented in the variably-saturated water flow and solute transport program HYDRUS-2D [12]. Non mechanistic models treat the $\mathrm{CW}$ as a "black box" where the interactions between atmosphere, soil, plants, water and micro organisms are not taking into account. In non mechanistic models, rules of thumb, regression equations, and equation of first-order reaction in an ideal plug flow reactor and its variations are found.

Rules of thumb are typical values of certain parameters of the wetlands from which the wetland surface can be calculated. Table 1 shows some values for HSSF and VSSF CW.

Table 1: Typical values for $\mathrm{CW}$ design.

\begin{tabular}{|c|c|c|c|}
\hline \multirow{2}{*}{ Reference } & \multicolumn{3}{|c|}{ HSSF CW } \\
\cline { 2 - 4 } & $\begin{array}{c}\text { Organic loading } \\
\left(\mathrm{g} \mathrm{BOD}_{5} \mathrm{~m}^{-2} \mathrm{~d}^{-1}\right)\end{array}$ & $\begin{array}{c}\text { Hydraulic loading } \\
\left(\mathrm{cm} \mathrm{d}^{-1}\right)\end{array}$ & $\begin{array}{c}\text { Specific area } \\
\left(\mathrm{m}^{2} \mathrm{PE}^{-1}\right)\end{array}$ \\
\hline$[13]$ & $<7.5$ & $0.2-0.3$ & - \\
\hline$[1]$ & - & $8-30$ & - \\
\hline$[14]$ & $<6$ & - & 5 \\
\hline$[9]$ & $<15$ & $<20$ & 1 (without nitrification) \\
\hline & \multicolumn{3}{|c|}{ VSSF CW } \\
\hline$[15]$ & - & - & 2 (with nitrification) \\
\hline$[15]$ & - & - & - \\
\hline$[16]$ & $<20$ & - & \\
\hline
\end{tabular}

For the VSSF CW, there are other tools similar to rules of thumb but they require a few mathematical operations. O'Hogain [17] calculated the area of two consecutive VSSF CWs with the eqns (1) and (2).

$$
\begin{gathered}
A_{1}=3.5 \cdot P E^{0.35}+0.6 \cdot P E \\
A_{2}=0.5 \cdot A_{1}
\end{gathered}
$$

where $A_{1}$ and $A_{2}$ are the area of the first a second VSSF CW, respectively, and $\mathrm{PE}$ is the population equivalent.

Noorvee et al. [18] calculated the area (A) of a single VSSF CW attending to the need for oxygen, using eqn (3).

$$
A=O D / V A
$$


where VA is the aeration potential of a VSSF CW, estimated in $30 \mathrm{~g} \mathrm{O}_{2} \mathrm{~m}^{-2} \mathrm{~d}^{-1}$ $[9,15]$, and $\mathrm{OD}$ is the oxygen demand $\left(\mathrm{g} \mathrm{O}_{2} \mathrm{~d}^{-1}\right)$ of the wastewater entering the wetland system and is calculated with eqn (4).

$$
O D=\left[\left(B O D_{\text {in }}-B O D_{\text {out }}\right)+\left(N H_{4}-N_{\text {in }}-N H_{4}-N_{\text {out }}\right) \cdot 4.3\right] \cdot Q
$$

where $\mathrm{Q}$ is the mean flow rate $\left(\mathrm{l} \mathrm{d}^{-1}\right)$ and $\mathrm{BOD}_{\text {in }}, \mathrm{BOD}_{\text {out }}, \mathrm{NH}_{4}-\mathrm{N}_{\text {in }}$ and $\mathrm{NH}_{4}-\mathrm{N}_{\text {out }}$ are the $\mathrm{BOD}_{7}\left(\mathrm{mg} \mathrm{O}_{2} \mathrm{l}^{-1}\right)$ and $\mathrm{NH}_{4}-\mathrm{N}\left(\mathrm{mg} \mathrm{N}^{-1}\right)$ concentrations at the inlet and outlet, respectively.

Inside the non mechanistic models, the more used one is the model of firstorder reaction in an ideal plug flow reactor $(\mathrm{K}-\mathrm{C})$, that can be modified $\left(\mathrm{K}-\mathrm{C}^{*}\right)$ including a background concentration $\left(\mathrm{C}^{*}\right)$ that represent the remaining nonbiodegradable pollutant [1]. This model is valid for both types of SSF CW if it is used in the areal form. According to this model, the area is calculated with eqn (5).

$$
A=\frac{Q}{K} \cdot \operatorname{Ln}\left(\frac{C_{i}-C^{*}}{C_{e}-C^{*}}\right)
$$

where $\mathrm{K}$ is the first order areal rate constant $\left(\mathrm{m} \mathrm{d}^{-1}\right)$ and $\mathrm{C}_{\mathrm{i}}$ and $\mathrm{C}_{\mathrm{e}}$ are the inlet and outlet concentration of the pollutant $\left(\mathrm{mg} \mathrm{l}^{-1}\right)$.

\section{Efficiency simulation of a hybrid CW system}

In this point, the results of a simulation of the treatment of a typical urban wastewater and a typical winery wastewater in a real $\mathrm{CW}$ system is shown using the $\mathrm{K}-\mathrm{C}^{*}$ model.

\subsection{Experimental installation}

The experimental installation was constructed in the Research and Development Centre for the Recuperation of the Environment (CIDRA) property of the company Alquimia Soluciones Ambientales, located in Daimiel, southern of Spain. In this centre, there were several systems of wastewater treatment; and one of them was a constructed wetlands system. The diagram of the experimental installation is shown in Figure 1.

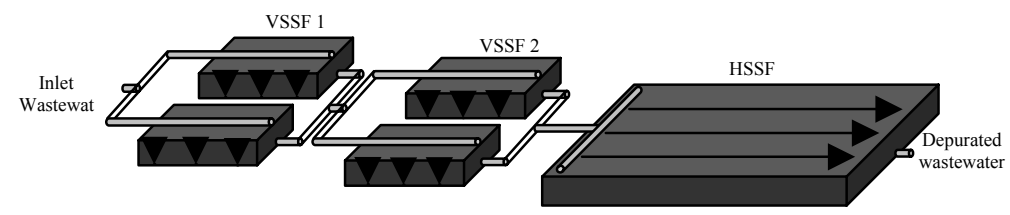

Figure 1: Diagram of the experimental installation.

It consists of two groups of double VSSF CW. The VSSF CWs have a dimension of $15 \mathrm{~m} \times 7.5 \mathrm{~m} \times 0.8 \mathrm{~m}(\mathrm{~L} \mathrm{x} \mathrm{W} \mathrm{x} \mathrm{H})$ and have a slope in the bottom of $1 \%$. They were filled with gravel with a particle size of $16-32 \mathrm{~mm}$ in the first $0.05 \mathrm{~m}$, beginning at the bottom. The rest was filled with gravel with a particle 
size of 4-6 mm. The HSSF has a dimension of $57.5 \mathrm{~m} \times 15 \mathrm{~m} \times 0.6 \mathrm{~m}(\mathrm{Lx} \mathrm{W} \times \mathrm{H})$ and has a slope of $1 \%$. It was filled with gravel with a particle size of 6-12 mm, except the first $2 \mathrm{~m}$ of the extremes of the wetland, that were filled with gravel with a particle size of $20-25 \mathrm{~mm}$ in order to obtain a good distribution of the inlet and outlet flow.

The first two VSSF CWs were fed in batch intermittently with a wastewater coming from an activated sludge treatment or a raw wastewater coming from a filtration system. Then, the effluent was fed in batch intermittently to the second two VSSF CWs. Finally, the effluent of these last VSSF CWs was fed to the HSSF CW continuously.

\subsection{Mathematical model}

Using the $\mathrm{K}-\mathrm{C}^{*}$ model, the concentration of compounds that suffer only a removal process, like Chemical oxygen demand (COD), total nitrogen (TN), organic nitrogen $\left(\mathrm{N}_{\text {org }}\right)$ and total phosphorous $(\mathrm{TP})$ can be calculated with the eqn (6), applying the corresponding $\mathrm{K}$ and $\mathrm{C}^{*}$ values of each compound. They are $\mathrm{K}_{\mathrm{C}}$ and $\mathrm{C}^{*}{ }_{\mathrm{C}}, \mathrm{K}_{\mathrm{N}}$ and $\mathrm{C}^{*}{ }_{\mathrm{N}}, \mathrm{K}_{\mathrm{ON}}$ and $\mathrm{C}^{*}{ }_{\mathrm{ON}}$ and $\mathrm{K}_{\mathrm{P}}$ and $\mathrm{C}^{*}{ }_{\mathrm{P}}$ for $\mathrm{COD}, \mathrm{TN}, \mathrm{N}_{\text {org }}$ and TP, respectively. Eqn (6) is the result of the solution of the mass balance equation for a steady state plug flow wetland [1].

$$
C_{e}=\left(C_{i}-C^{*}\right) \cdot \exp (-K \cdot A / Q)+C^{*}
$$

But, in the calculation of the concentration of compounds that appear and disappear at the same time because of the act of different processes, other positive terms have to be added in the mass balance. This is the case of ammonium $\left(\mathrm{N}_{-} \mathrm{NH}_{4}^{+}\right)$, which appears because of the ammonification of $\mathrm{N}_{\text {org }}$ and disappear in the nitrification process, and nitrate $\left(\mathrm{N}_{-} \mathrm{NO}_{3}{ }^{-}\right)$, which appears in the nitrification and disappears in the denitrification one. The effluent concentrations of these compounds were calculated with eqns (7) and (8), which are a result of the solutions of the mass balances of each one [1].

$$
\begin{gathered}
C_{A N}=C_{A N}^{*}+\left(C_{A N, i}-C_{A N}^{*}\right) \cdot e^{\left(-y \cdot K_{A N} \cdot A / Q\right)}, \\
+\left(\frac{K_{O N}}{K_{A N}-K_{O N}}\right) \cdot\left(C_{O N, i}-C_{O N}^{*}\right) \cdot\left(e^{\left(-y \cdot K_{O N} \cdot A / Q\right)}-e^{\left(-y \cdot K_{A N} \cdot A / Q\right)}\right) . \\
C_{N N}=C_{N N}^{*}+\left(C_{N N, i}-C_{N N}^{*}\right) \cdot e^{\left(-y \cdot K_{N N} \cdot A / Q\right)}, \\
+\left\{\begin{array}{c}
\left(\frac{K_{A N}}{K_{N N}-K_{A N}}\right) \cdot\left(C_{A N, i}-C_{A N}^{*}\right) \cdot\left(e^{\left(-y \cdot K_{A N} \cdot A / Q\right)}-e^{\left(-y \cdot K_{N N} \cdot A / Q\right)}\right) \\
+\left(\frac{K_{O N}}{K_{A N}-K_{O N}}\right) \cdot\left(C_{O N, i}-C_{O N}^{*}\right) \cdot\left(e^{\left(-y \cdot K_{O N} \cdot A / Q\right)}-e^{\left(-y \cdot K_{N N} \cdot A / Q\right)}\right) \\
-\left(\frac{K_{O N}}{K_{A N}-K_{O N}}\right) \cdot\left(\frac{K_{A N}}{K_{N N}-K_{A N}}\right) \cdot\left(C_{O N, i}-C_{O N}^{*}\right) \cdot\left(e^{\left(-y \cdot K_{A N} \cdot A / Q\right)}-e^{\left(-y \cdot K_{N N} \cdot A / Q\right)}\right)
\end{array}\right\}
\end{gathered}
$$


where $\mathrm{C}_{\mathrm{NN}}$ and $\mathrm{C}_{\mathrm{AN}}$ are the nitrate and ammonium concentrations, respectively, $\mathrm{K}_{\mathrm{AN}}$ and $\mathrm{C}^{*}{ }_{\mathrm{AN}}, \mathrm{K}_{\mathrm{NN}}$ and $\mathrm{C}^{*}{ }_{\mathrm{NN}}$ are the parameters of nitrification and denitrification, respectively, and $\mathrm{y}$ is the fraction distance through the wetland. Eqn (8) is used to calculate $\mathrm{N}_{-} \mathrm{NO}_{3}{ }^{-}$concentration considering that there is no volatilization of $\mathrm{N}_{-} \mathrm{NH}_{4}{ }^{+}$, assuming low temperature and $\mathrm{pH}$ values [1]. The used parameter values were given by Vymazal et al. [9] for VSSF CW, and, for HSSF CW, were calculated by Mena [19]. Both of them are shown in Table 2.

Table 2: $\quad$ Parameter values used in the model.

\begin{tabular}{|c|c|c|c|c|}
\hline Parameter & $\mathrm{K}_{\mathrm{C}}\left(\mathrm{m} \mathrm{year}^{-1}\right)$ & $\mathrm{C}^{*}{ }_{\mathrm{C}}\left(\mathrm{mg} \mathrm{l}^{-1}\right)$ & $\mathrm{K}_{\mathrm{N}}\left(\mathrm{m} \mathrm{year}^{-1}\right)$ & $\mathrm{C}^{*_{\mathrm{N}}}\left(\mathrm{mg} \mathrm{l}^{-1}\right)$ \\
\hline VSSF CW & 80.3 & 30 & 16 & 0 \\
\hline HSSF CW & 72.7 & 30 & 10.6 & 3.9 \\
\hline Parameter & $\mathrm{K}_{\mathrm{P}}\left(\mathrm{m} \mathrm{year}^{-1}\right)$ & $\mathrm{C}_{\mathrm{P}}\left(\mathrm{mg} \mathrm{l}^{-1}\right)$ & $\mathrm{K}_{\mathrm{ON}}\left(\mathrm{m} \mathrm{year}^{-1}\right)$ & $\mathrm{C}^{*}{ }_{\mathrm{ON}}\left(\mathrm{mg} \mathrm{l}^{-1}\right)$ \\
\hline VSSF CW & 6.5 & 1 & 74.1 & 0 \\
\hline HSSF CW & 7.8 & 1 & 74.1 & 0 \\
\hline Parameter & $\mathrm{K}_{\mathrm{AN}}\left(\mathrm{m} \mathrm{year}^{-1}\right)$ & $\mathrm{C}^{*}{ }_{\mathrm{AN}}\left(\mathrm{mg} \mathrm{l}^{-1}\right)$ & $\mathrm{K}_{\mathrm{NN}}\left(\mathrm{m} \mathrm{year}^{-1}\right)$ & $\mathrm{C}^{*}{ }_{\mathrm{NN}}\left(\mathrm{mg} \mathrm{l}^{-1}\right)$ \\
\hline VSSF CW & 25 & 0 & 16 & 0 \\
\hline HSSF CW & 7.0 & 0 & 227.5 & 0.8 \\
\hline
\end{tabular}

Typical urban and winery wastewater compositions used in the simulations are shown in Table 3.

Table 3: $\quad$ Composition of each wastewater in $\mathrm{mg} \mathrm{l}^{-1}$.

\begin{tabular}{|c|c|c|c|c|}
\hline & COD & TN & TP & $\mathrm{N}_{\text {org }}$ \\
\hline Urban [20] & 740 & 80 & 23 & 30 \\
\hline Winery [21] & 7500 & 130 & 55 & 45 \\
\hline & ${\mathrm{N}-\mathrm{NH}_{4}{ }^{+}}$ & ${\mathrm{N}-\mathrm{NO}_{3}{ }^{-}}^{-}$ & $\mathrm{TKN}$ & $\mathrm{pH}$ \\
\hline Urban [20] & 50 & 0 & 80 & $7-8$ \\
\hline Winery [21] & 85 & 0 & 130 & $6-7$ \\
\hline
\end{tabular}

\section{Results and discussion}

Once the dimensions of the CWs and wastewater compositions were determined, the only not defined parameters were the flow rate and the required outlet concentration. Figure 2 shows the values of the concentrations of COD, TN and $\mathrm{TP}$ for each flow rate and the discharge limit according to the European Directive 91/271/CEE.

Table 4 shows maximum flow rates to obtain an effluent suitable for the discharge attending to different pollutant requirements.

As can be seen in Figure 2 and Table 4, the winery wastewater requires lower flow rate to reach the discharge limits because of its higher loading. Moreover, $\mathrm{TP}$ is the parameter that limit stricter the flow rate. Because of this fact, the main part of the wetlands was designed only for nitrogen and COD removal. For the TP removal, an interchangeable module of a material with high potential of phosphate precipitation can be used [1]. Regarding the maximum value of the organic loading in the VSSF CW, showed in Table 1, the maximum flow rates were 12.9 and $1 \mathrm{~m}^{3} \mathrm{~d}^{-1}$ for urban and winery wastewater treatment, respectively. 
Despite this recommendation, many experiments successfully treated wastewater with higher organic loading (up to $75 \mathrm{~g} \mathrm{BOD}_{5} \mathrm{~m}^{-2} \mathrm{~d}^{-1}[22]$ ).

COD

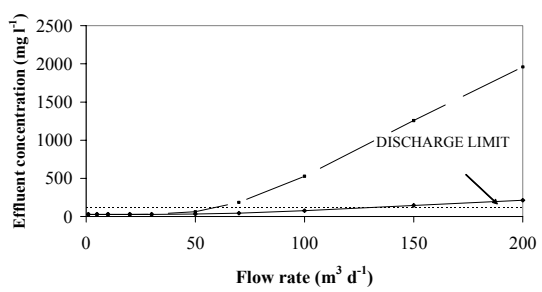

TN
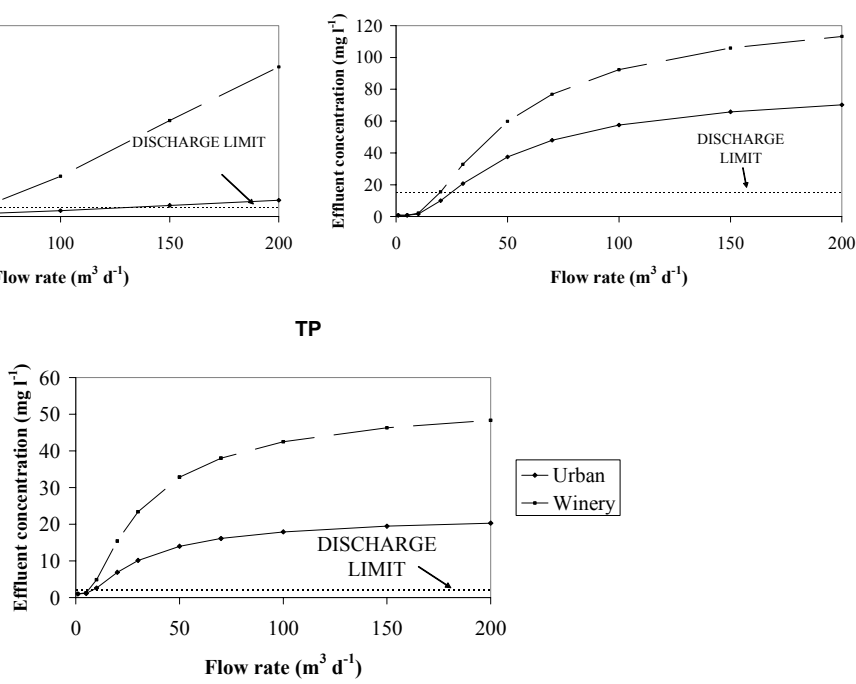

Figure 2: $\quad$ Effluent concentration of COD, TN, TP for each flow rate.

Table 4: $\quad$ Maximum flow rates $\left(\mathrm{m}^{3} \mathrm{~d}^{-1}\right)$ to obtain an effluent suitable for the discharge for each wastewater attending to different pollutant discharge.

\begin{tabular}{|c|c|c|}
\hline & Urban & Winery \\
\hline COD & 134.6 & 62.0 \\
\hline TN & 24.6 & 19.7 \\
\hline TP & 8.5 & 6.6 \\
\hline
\end{tabular}

Figure 3 shows the variations of the concentration of the different pollutants calculated for the urban wastewater treatment using the model $\mathrm{K}-\mathrm{C}^{*}$ inside each $\mathrm{CW}$ for the flow rate that achieved the discharge limit of nitrogen and COD $\left(24.6 \mathrm{~m}^{3} \mathrm{~d}^{-1}\right)$. As can be seen in this Figure, HSSF CW had a faster removal of COD than the VSSF one. However, the value of VSSF removal rate was higher than that of the HSSF one. This is because the HSSF has higher area and hydraulic residence time.

In the VSSF CWs, the main part of the $\mathrm{N}_{\text {org }}$ was hydrolyzed forming $\mathrm{N}-\mathrm{NH}_{4}{ }^{+}$. As a consequence, a slight increase of its concentration was observed in the VSSF CW 1. At the same time, the $\mathrm{N}_{-} \mathrm{NH}_{4}{ }^{+}$was being nitrified, increasing the $\mathrm{N}-\mathrm{NO}_{3}{ }^{-}$concentration considerably. The entire formed $\mathrm{N}-\mathrm{NO}_{3}{ }^{-}$was removed in the HSSF CW by denitrification, which was the only mechanism that eliminated $\mathrm{TN}$ from the $\mathrm{CW}$. 
For the TP removal, a similar behaviour was observed. A faster removal in the HSSF CW was obtained because of its higher hydraulic residence time.
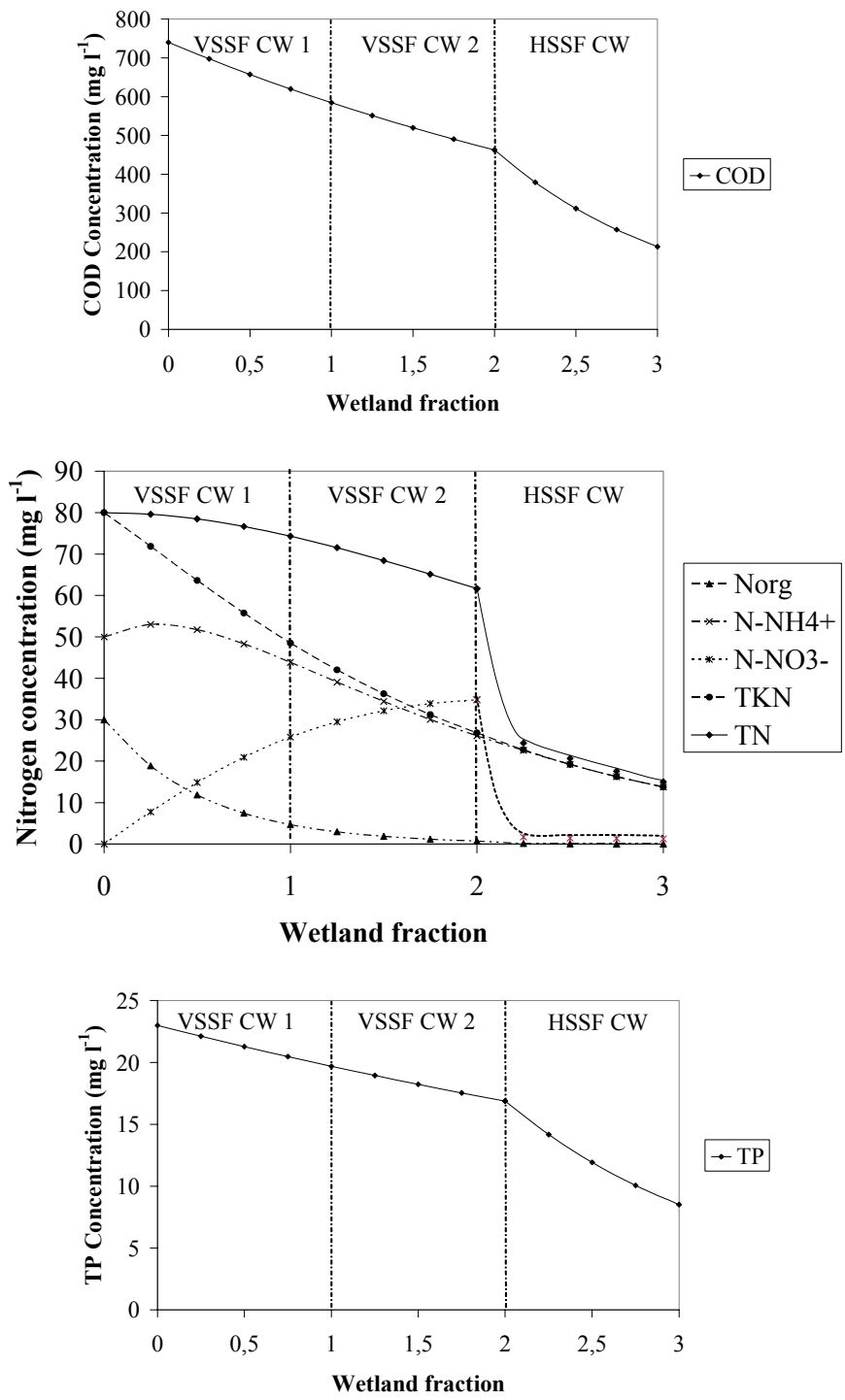

Figure 3: $\quad$ Pollutant concentration profile of the urban wastewater treatment with a flow rate of $24.6 \mathrm{~m}^{3} \mathrm{~d}^{-1}$. 


\section{Conclusions}

Simulation of wastewater treatment with non-mechanistic models helped to the comprehension of the different processes occurring in constructed wetlands and can act as a preliminary design tool. In the simulations, winery wastewater treatment required lower flow rates because of its higher organic loading. Because constructed wetlands had limited capacity to remove phosphorous, this compound was the most restrictive pollutant, requiring a lower flow rate.

\section{References}

[1] Kadlec, R.H. \& Knight, R.L., Treatment Wetlands, Lewis Publishers: New York, 1996.

[2] Brix, H. \& Schierup, H.H., Soil oxygenation in constructed reed beds: the role of macrophyte and soil-atmosphere interface oxygen transport. Water Research, 29, pp. 259-266, 1990.

[3] Armstrong, W., Armstrong, J. \& Beckett, P.M., Measurement and Modelling of Oxygen Release from Roots of Phragmites Australis. In: Constructed Wetlands in Water Pollution Control, P.F. Cooper and B.C. Findlater (Eds.), Pergamon Press, Oxford, England, pp. 41-52, 1990.

[4] García J., Ojeda E., Sales E., Chico F., Píriz T., Aguirre P. \& Mujeriego R., Spatial variations of temperature, redox potential and contaminants in horizontal flow reed beds. Ecological Engineering, 21, pp. 129-142, 2003.

[5] Villaseñor, J., De Lucas, A., Gómez, R. \& Mena, J., A Comparative Study of Five Horizontal Subsurface Flow Constructed Wetlands using Different Plant Species for Domestic Wastewater Treatment. Environ. Tech., 28(12), pp. 1333-1343, 2007.

[6] Xu, D., Xu, J., Wu, J. \& Muhammad, A., Studies on the phosphorus sorption capacity of substrated used in constructed wetlands systems. Chemosphere, 63, pp. 344-352, 2006.

[7] Molle, P., Liénard, A., Grasmick, A. \& Iwema, A., Phosphorus retention in subsurface constructed wetlands: investigations focused on calcareous materials and their chemical reactions. Wat. Sci. Tech., 48, pp. 75-83, 2003.

[8] Calder, N., Anderson, B.C. \& Martin D.G., Field investigation of advanced filtration for phosphorus removal from constructed treatment wetlands effluents. Environ. Tech., 27, 1063-1071, 2006.

[9] Vymazal, J., Brix, H., Cooper, P.F., Green, M.B. \& Haberl, R., (eds). Constructed wetlands for wastewater treatment in Europe, Backhuys Publishers: Leiden, The Netherlands, 1998.

[10] Rousseau, D.P.L., Vanrolleghem, P.A. \& De Pauw, N., Model-based design of horizontal subsurface flow constructed treatment wetlands: a review. Wat. Res., 38, pp. 1484-1493, 2004.

[11] Langergraber, G., Development of a simulation tool for subsurface flow constructed wetlands. Wiener Mitteilungen, 169, Vienna, pp. 207, 2001 [in German]. 
[12] Langergraber, G. \& Šimůnek, J., Modelling variably saturated water flow and multicomponent reactive transport in constructed wetlands. Vadose Zone J., 4(4), pp. 924-938, 2005.

[13] Wood, A., Constructed wetlands in water pollution control: fundamentals to their understanding. Wat. Sci. Technol., 32 (3), pp. 21-29, 1995.

[14] U.S. Environmental Protection Agency. Constructed Wetland Treatment of Municipal Wastewater, U.S. Environmental Protection Agency: Cincinnati, 2000.

[15] Cooper, P., A review of the design and performance of vertical-flow and hybrid reed bed treatment systems. Wat. Sci. and Tech., 40(3), pp. 1-9, 1999.

[16] Winter, K.J., Goetz, D., The impact of sewage composition on the soil clogging phenomena of vertical flow constructed wetlands. Wat. Sci. Tech. 48 (5), pp. 9-14, 2003.

[17] O'Hogain, S., The Design, Operation and Performance of a Municipal Hybrid Reed Bed Treatment. Wat. Sci. and Tech., 48 (5), pp. 119-126, 2003.

[18] Noorvee, A., Poldvere, E. \& Mander, Ü., The effect of a vertical flow filter bed on a hybrid constructed wetland system. Wat. Sci. and Tech., 51 (9), pp. 137-144, 2005.

[19] Mena, J., Tratamiento de aguas residuales urbanas y vinícolas con humedales artificiales. PhD work, Ciudad Real, 2008 [in Spanish].

[20] Villaseñor, J., Eliminación biológica de fósforo en aguas residuales urbanas. PhD work, Ciudad Real, 1998 [in Spanish].

[21] García Morales, J.L., Personal Communication, Depuración de vertidos de destilerías vínicas, UCLM, Puertollano, 2003.

[22] Brix, H., Sorrell, B.K. \& Orr, P.T., Internal pressurization and convective gas flow in some emergent freshwater macrophytes. Limnol. Oceanogr., 37, pp. 1420-1433, 1992. 